\title{
Neonatal behavioral assessment among survivors of birth asphyxia using T.Berry Brazelton's NBAS
}

\author{
S. Radhakrishnan ${ }^{1}$, S. Brinda ${ }^{2}$, M. Singaravelu ${ }^{3}$ \\ ${ }^{1}$ Dr. S. Radhakrishnan, Resident, Department of Neonatology, ICH \& HC, Chennai Egmore. ${ }^{2}$ Dr. S. Brinda, Assistant \\ Professor of Pediatrics, Thanjavur Medical College, Thanjavur, ${ }^{3}$ Dr. M. Singaravelu, Professor and Head of the \\ Department of Pediatrics, Manakula Vinayagar Medical College, Pondy, Kalitheerthalkuppam, Madagadipet, \\ Puducherry, 605107, India.
}

Address for Correspondence: Dr. S. Brinda, Plot No:17, Arokiasamy Nagar, Kumbakonam. E-mail: drbrindasiva@gmail.com

\begin{abstract}
Introduction: This study aims at providing baby-specific prognosisfor the survivors of birth asphyxia,regarding their neurological impairment, based on their behaviour assessment using T. Berry Brazelton's NBAS. Methods: 56 HIE survivors were randomly selected and grouped into 3 as HIE 1,2,3 based on Sarnat HIE staging. NBAS was scored just before discharge which consists of 28 behavior items \& 7 supplementary items ( 9 points scale) and 18 reflex items (4point scale). Scores calculated and compared between groups. Results: The average score of HIE 1 babies were $65.01 \%$, HIE 2 babies were $58.01 \%$ and that of HIE 3 babies were $41.75 \%$. 60\% of HIE 3 babies made a score less than $40 \% .73 \%$ of HIE 2 babies scored between $50 \%$ and $60 \%$. 88\% of HIE 1 babies scored between $60 \%$ and $70 \%$. More than $50 \%$ of HIE 1 babies had an abnormal reflex score less than 5 while more than $60 \%$ of HIE 2 babies scored between 6 and 10 . HIE 3 were the worst to perform where 3 out of 5 babies scored $>11$. Sex of the babies, their birth weight and the mode of delivery showed no statistical significance for comparing them against the final \% scores. Lower final scores were associated with higher abnormal reflex scores and vice versa. Conclusions: NBAS helps us to prognosticate a baby individually rather than relying on past personal experience on the treating neonatologist or the available non-directive statistics. Every birth asphyxia survivor needs to be administered NBAS before discharge from hospital. By identifying the strength one can boost the mother's confidence in looking after the child and ease the rehabilitation and further intervention as would be required.
\end{abstract}

Key words: Birth Asphyxia, Neurobehavioral Assessment, Prognostic indicator

\section{Introduction}

Birth asphyxia is a major public health problem.It accounts for $9 \%$ of total under five mortalities.It is one of the three most common causes of neonatal deaths, others being prematurity and bacterial infection [1] of a total 2.7 million still births globally, approximately 1.2 million occur during intra-partum period owing to birth asphyxia [2, 3]. NNPD (2002-2003) reported birth asphyxia as the commonest cause of still births, accounting for $45.1 \%$ of all such cases [4].

As there is no single definition for birth asphyxia, widely available various definitions were reviewed and babies HIE status was classified as per Sarnat and Sarnat classification [3-12]. The overall mortality of

Manuscript received: $28^{\text {th }}$ April 2018

Reviewed: $6^{\text {th }}$ May 2018

Author Corrected: $14^{\text {th }}$ May 2018

Accepted for Publication: $17^{\text {th }}$ May 2018
HIE is $20 \%$ and the possibility of sequelae among survivors is $30 \%$ [13]. According to Sarnat and Sarnat staging, HIE 1 have a mortality of $<1 \%$ and $98 \%-100 \%$ normal neurological outcome. HIE 2 babies pose a risk of death / abnormal neurological outcome in the range of $20-37 \%$. In HIE 3, death is more likely and survivors can have major disability [13]. These data were based on personal past experience of treating neonatologist and the non-directive statistics.Therefore, in order to provide prognosis to each birth asphyxia survivor, a more detailed scoring system would be necessary. That's where T. Berry Brazelton's NABS comes to rescue.

NBAS (Neonatal Behavior Assessment Scale [14]: Earlier it was thought, babies were passive recipients of sensory stimulation, responding to environmental input 
Editorial

with innate reflexes. In other words, newborn babies were just "lumps of clay" ready to be shaped by the environment based on their genetic potential. NBAS assumes that the newborn is a social organism, predisposed to interact with her caregiver from the beginning and be able to elicit the kind of caregiving necessary for her species-specific survival and adaptation [14]. NBAS describes the full range of neonatal behaviour, including competencies and strengths as well as identifying areas of difficulty or deviation.

NBAS is a neurobehavioral assessment scale which is designed to describe neonate's responses to their new extra-uterine environment and to document the contribution of the newborn baby to the development of the emerging parent-child relationship. So the study was designed to objectively document the behaviour pattern of birth asphyxiated babies and to assess how worse the behavior is derailed according to the severity of HIE.

\section{Materials and Methodology}

Place of study: Neonatal Intensive Care Unit at Rajamirasudhar Hospital attached to Thanjavur Medical College, Thanjavur.

Study design: Cross sectional observational study.

Period of study: March 2015 - August 2015.

Sampling method: Simple random sampling

Inclusion criteria: Term birth asphyxia babies who were fit for discharge after intensive care treatment atNeonatal Intensive Care Unit at Rajamirasudhar Hospital attached to Thanjavur Medical College between Mar 2015 - Aug 2015 were included.

Exclusion criteria: Birth asphyxia survivors with associated co-morbidities like sepsis, jaundice, congenital anomalies and preterm were excluded as they themselves might influence NBAS scores.

The selected babies were grouped based on sarnat and sarnat HIE staging as HIE 1 (mild), 2 (moderate) and 3(severe). Babies were examined midway between feedings in a quite semi-darkened room with room temperature around $22-27^{\circ} \mathrm{C}$ in the presence of the infant's mother. The optimal time to administer NBAS is $2^{\text {nd }}$ or $3^{\text {rd }}$ day of life but in our study. It was applied when babies were fit to be discharged from intensive care unit as it is equally important to consider that NBAS should not be attempted for babies in NICU with multichannel monitors, IV fluids and oxygen etc.
Final scores were modified using Lester's seven cluster scoring system. The scores between the groups were compared.

NBAS Testing Kit: Consists of a red ball, a rattle, a bell, a foot probe and a torch. (available at http:// www.brazelton-institute.com/order.html)

Administration of NBAS: NBAS consists of 28 behavioral items (scored on a 9-point scale), 7 supplementary items (scored on a 9-point scale) and 18 reflex items (scored on a 4 points scale).

These items are grouped into 5 packages viz, a) The habituation package b) The motor-oral package c) The truncal package d) The vestibular package ande) The social interactive package.

The administration of NBAS begins with observation of the initial state. The baby could be in any one of the 6 states - state 1 deep sleep; state 2 light sleep; state 3 drowsy; state 4 alert; in state 5 the baby has considerable motor activity and state 6 which is crying.

a) In habituation package, the infant's capacity to shut out the negative stimuli is assessed. One of the most impressive mechanisms in the neonate is the capacity to decrease response to repeated disturbing stimuli. Here response decrement to light, to rattle, to bell, to tactile stimulation of foot is assessed.

b) The motor-oral package contains minimally intrusive items which includes reflexes of the feet and rooting, sucking and glabella items. Therefore, plantar reflex, babinski response, ankle clonus, passive tone in legs and in arms, rooting response, sucking reflex and glabella response is tested.

c) The truncal package- this package includes moderately stimulating items. Here palmar grasp, pull to sit, placing reflex, standing reflex, walking reflex, crawling reflex, incurvation reflex, tonic deviation of head, eyes, nystagmus and cuddliness are assessed.

d) The vestibular package- includes maximal handling and stimulating items. Here defensive movement, tonic neck reflex, moro reflex is assessed.

e) The social interactive package- includes all the orientation items. Here animate visual, animate visual and auditory, inanimate visual, inanimate visual and auditory, animate auditory and inanimate auditory is assessed. 


\section{Editorial}

Scoring of the NBAS items: For each item administered, scoring has to be done so that objective documentation of the baby's response is possible. The scoring system of NBAS is not always straight forward. In few items like general tonus, a mid level score would mean a good response and a score on either side would be abnormal. And in few others like tremulousness, a high score would indicate a bad picture while a low score means, the baby is doing well. To make things straight and thereby the scores become simpler,the NBAS scoring has been modified by Lester et al[15].

\section{Results}

A total of 56 babies who were treated for birth asphyxia during the study period were included. The sample consisted of 35 boys and 21 girl babies. $25 \%$ of the sample were $<2.5 \mathrm{~kg}$ birth weight while the rest were $>2.5 \mathrm{~kg}$. $62.5 \%$ of the babies were delivered by labour natural, $21.4 \%$ by outlet forceps and the rest $16.1 \%$ were by LSCS. The babies were grouped into three HIE stages based on Sarnat and Sarnat classification.

Of the total 56, 25 babies were labelled HIE 1, 26 as HIE 2 and just 5 as HIE 3. When these babies were deemed fit for discharge from hospital, NBAS was administered in the presence of their mother and scores calculated. NBAS consists of a total of 53 parameters. The final percentage scores were later subjected to Lester's modification. Among the behavior items, statistical significance for difference among HIE stages was seen in all parameters observed except in response decrement to tactile stimulation of the foot, auditory inanimate orientation, peak excitement and rapidity of build-up and startles. Among the supplementary items except for examiner facilitation all other items showed a statistical significance for the differences observed between the HIE stages.

As per Lester's modification, the average score of HIE 1 babies were $65.01 \%$, HIE 2 babies were $58.01 \%$ and that of HIE 3 babies were $41.75 \% .50 \%$ of the sample had a final score between 60 and $70 \%$ and another $37.5 \%$ of the sample scored between 50 and $60 \%$. The remaining fell on the either sides. The differences were statistically significant as shown in the table below.

Table- 1: Frequency distribution of the observed values \% score.

\begin{tabular}{|c|c|c|}
\hline Particulars & $\begin{array}{c}\text { Frequency } \\
(\mathbf{n = 5 6 )}\end{array}$ & Percent (100\%) \\
\hline Below 39.99 & 3 & 5.4 \\
\hline 40 to 49.99 & 3 & 5.4 \\
\hline 50 to 59.99 & 21 & 37.5 \\
\hline 60 to 69.99 & 28 & 50.0 \\
\hline $70 \&$ above & 1 & 1.8 \\
\hline
\end{tabular}

$75 \%$ of the selected babies had an abnormal reflex score below 5 and $5 \%$ had score above 11 . The rest were between the cut-offs as shown in the table below. There is statistical significant difference between the HIE stages and the abnormal reflex scores observed. $>50 \%$ of HIE 1 babies had abnormal reflex score less than 5 while $>60 \%$ of HIE 2 babies scored between 6 and 10. HIE 3 were the worst to perform where 3 of 5 babies scored $>11$.

Eight of the eighteen reflex items did not show statistical significance for the differences observed. However, the final abnormal reflex score marked using Lester's modification showed a statistically significant difference between the HIE stages.

Table- 2: Abnormal Reflex score.

\begin{tabular}{|c|c|c|}
\hline Particulars & $\begin{array}{c}\text { Frequency } \\
(\mathbf{n = 5 6 )}\end{array}$ & Percent (100\%) \\
\hline Below 5 & 42 & 75.0 \\
\hline 6 to 10 & 11 & 19.6 \\
\hline 11 \& above & 3 & 5.4 \\
\hline
\end{tabular}

Lower final scores were associated with higher abnormal reflex scores and vice-versa. The association was statistically significant. 
Editorial

Table- 3: Percentagescore * Reflex score.

\begin{tabular}{|c|c|c|c|c|c|}
\hline \multirow[b]{2}{*}{$\%$ score } & \multicolumn{4}{|c|}{ Reflex score } & \multirow[b]{2}{*}{ Statistical inference } \\
\hline & $\begin{array}{c}\text { Below } 5 \\
(n=42)\end{array}$ & $\begin{array}{l}6 \text { to } 10 \\
(n=11)\end{array}$ & $\begin{array}{c}11 \& \text { above } \\
(n=3)\end{array}$ & $\begin{array}{c}\text { Total } \\
(n=56)\end{array}$ & \\
\hline Below 39.99 & 0 & $1(9.1 \%)$ & $2(66.7 \%)$ & $3(5.4 \%)$ & \multirow{5}{*}{$\begin{array}{c}\mathrm{X} 2=32.247 \mathrm{Df}=8 \\
.000<0.05 \\
\text { Significant }\end{array}$} \\
\hline 40 to 49.99 & $1(2.4 \%)$ & $1(9.1 \%)$ & $1(33.3 \%)$ & $3(5.4 \%)$ & \\
\hline 50 to 59.99 & $17(40.5 \%)$ & $4(36.4 \%)$ & 0 & $21(37.5 \%)$ & \\
\hline 60 to 69.99 & $23(54.8 \%)$ & $5(45.5 \%)$ & 0 & $28(50 \%)$ & \\
\hline $70 \&$ above & $1(2.4 \%)$ & 0 & 0 & $1(1.8 \%)$ & \\
\hline
\end{tabular}

Sex of the babies, their birth weight and the mode of delivery showed no statistical significance for comparing them against the final \% scores.

\section{Discussion}

Birth asphyxia significantly puts a baby off - track in terms of their behavior which can be very well be assessed clinically and be documented objectively using T. Berry Brazelton's Neonatal Behavior Assessment Scale (NBAS). NBAS helps to prognosticate a baby individually rather relying on past experience or nondirective statistics. When the mother receives her sick baby who has just recovered from NICU, she may not be confident enough to handle her baby. She needs lots of support from hospital team. NBAS demonstrates the strengths of the baby, by doing so the mother would feel more confident to handle her baby thereby promoting parent-child relationship. Apart from strength, NBAS also demonstrates the weakness and areas of concern of the baby, thereby early rehabilitation and interventions becomes possible. Therefore, every birth asphyxia survivor needs to be administered NBAS before discharge to identify the strengths and weakness of the baby for appropriate interventions at the earliest.

NBAS is a research tool used extensively by many researches across the globe. Some of the pioneer studies were by Black et al[16] who demonstrated the effects of maternal substance abuse on infant behavior and development using NBAS. Mansi et al[17] looked at the effect of maternal smoking in pregnancy. Babies of smoking mothers had lower scores in many NBAS items and a strong correlation between infant's irritability and urinary cocaine in newborn.

Ober et al[18] studied the effect of prenatal alcohol on babies and reported a blunted response to noxious stimulus among the exposed babies in terms of lower heart rate and reduced cortisol levels. Tronicetal.,[19] showed that by using NBAS at 2-3 weeks of age it's possible to say if the baby's mother is depressed or not. A baby whose mother is depressed will not make proper eye contact, may even avoid gaze and may exhibit distress by spitting up during interactions with mother. The baby will be withdrawn unless the mother's depression is addressed to. Once the mother recovers the baby can be engaged more easily. Thus, NBAS is an effective prognosticator clinical tool to interpret the behavioral outcome of babies who survive a painful and stressful event as birth asphyxia. But the limitations of this studyis that, a small sample size, one time observation study, may not completely depict the behavior of the baby in one sitting and there was no follow up of these babies and limited literature on NBAS administered on birth asphyxia babies.

\section{Conclusion}

NBAS is a clinical tool with which one can objectively document the behavior repertoire of a newborn baby. In this study, by observing the behavior pattern of asphyxiated babies an attempt was made to explain their prognosis. It was found that severe the perinatal insult, severe is their behavioral derailment and vice versa.

What this study adds?

It is possible that every birth asphyxia baby can be objectively tested for their neuro behavior pattern following an insult, therefore every birth asphyxia survivor needs to be administered NBAS before discharge to identify the strength and weakness of the baby for appropriate interventions at the earliest.

Contributors: RS: Recruited patients, collected data and manuscript writing. BS: Analysed the data and reviewed the manuscript. She will serve as guarantor of the study. SM: Finalised and supervised the study.

Abbreviations: HIE-HypoxicIschemicEncephalopathy. NBAS- Neonatal Behavioral Assessment Scale.

Funding: Nil, Conflict of interest: None initiated, Perission from IRB: Yes 


\section{References}

1. Black RE, Cousens S, Johnson HL, Lawn JE, Rudan I, Bassani DG, Jha P, Campbell H, Walker CF, Cibulskis R, Eisele T, Liu L, Mathers C; Child Health Epidemiology Reference Group of WHO and UNICEF. Global, regional, and national causes of child mortality in 2008: a systematic analysis. Lancet. 2010Jun5; 375 (9730) : 1969-87. doi: 10.1016/S0140-6736(10)605491. Epub2010 May 11.

2. Lawn JE, Blencowe H, Pattinson R, Cousens S, Kumar R, Ibiebele I, Gardosi J, Day LT, Stanton C; Lancet's Stillbirths Series steering committee. Still births: Where? When? Why? How to make the data count? Lancet. 2011 Apr 23;377 (9775):1448-63. doi: 10. 1016/S0140-6736(10)62187-3. Epub 2011 Apr 13.

3. WHO. Perinatal Mortality: A Listing of Available Information.WHO;Geneva:1996.WHO/FRH/MSM/96.7

4. National neonatal perinatal database NNPD 2002-03. Indian Council of Medical Research, New Delhi. January 2005.

5. Use and abuse of the Apgar score. Committee on Fetus and Newborn, American Academy of Pediatrics, and Committee on Obstetric Practice, American College of Obstetricians and Gynecologists Paediatrics. 1996 Jul; 98(1):141-2.

6. MacLennan A. A template for defining a causal relation between acute intrapartum events and cerebral palsy: international consensus statement.BMJ.19990ct 16; 319 (7216):1054-9.

7. Peter Van Eerden, MD; Peter S. Bernstein Summary of the Publication. Neonatal Encephalopathy and Cerebral Palsy: Defining the Pathogenesis and Pathophysiology by the ACOG Task Force on Neonatal Encephalopathy and Cerebral Palsy July 03, 2003.

8. Nageswara Prasad Vunnava. Chap 28. Essentials of Neonatal Emergencies and Clinical Guidelines Paper back- 31 Jan 2013.

9. Sarnat HB, Sarnat MS. Neonatal encephalopathy following fetal distress. A clinical and electro encephalo graphic study. Arch Neurol. 1976 Oct;33(10):696-705.
10. Levene MI. The asphyxiated newborn. In.: Levene MI, Lilford RJ. F et al and neonatal neurology and neurosurgery. Edinburg: Churchill livingstone1995; 405-26.

11. Thompson CM, Puterman AS, Linley LL, Hann FM, van der Elst CW, Molteno CD, Malan AF. The value of a scoring system for hypoxic ischaemic encephalopathy in predicting neuro developmental outcome. Acta Paediatr. 1997 Jul;86(7):757-61.

12. Robertson CM, Finer NN. Long-term follow-up of term neonates with perinatal asphyxia. Clin Perinatol. 1993 Jun; 20(2):483-500.

13. John P Cloherty, Lippincott Williams \& Wilkins. Manual of neonatal care 7 the dition Chap 55, 25-26.

14. Brazelton, T. Berry; Nugent, J. Kevin. Neonatal behavioral assessment scale (4th ed.). London: Mac Keith Press. ISBN 978-1-907655-03-6.oct 2011.

15. Lester et al $(1982,84)$. Lester BM. Data analysis and prediction. In: Brazelton TB, Neonatal behavioral assessment scale 2nd ed, London, Mac Keith Press.

16. Black M, Schuler M, Nair P. Prenatal drug exposure : neurodevelopmental outcome and parenting environment. J Pediatr Psychol. 1993 Oct; 18(5): 605-620.

17.MansiG,RaimondiF,PichiniS, CapassoL, SarnoM, Z uccaroP, PacificiR, GarciaAlgarO, RomanoA, Paludetto R. Neonatal urinary continence correlates with behavioral alterations with newborns prenatally exposed to tobacco smoke. Pediatr Res. 2007 Feb;61 (2):257-61.

18. Tim F. Oberlander, Sandra W. Jacobson, Joanne Weinberg, Ruth E. Grunau, Christopher D. Molteno, and Joseph L. Jacobson. Prenatal alcohol exposure alters behavioural reactivity to pain in newborns. Alcohol clin exp res 34:681-692. Published online 2010 Jan 27. doi: 10.1111/j.1530-0277.2009.01137.x.

19. Tronic EZ. The Neurobehavioral and SocialEmotional Development of Infants and Children Ed Tronick, W. W. Norton \& Company: New York, NY, 2007. 571 pp, CA \$68.00.J Can Acad Child Adolesc Psychiatry. 2009 Aug; 18(3): 263-264.

\section{How to cite this article?}

S. Radhakrishnan, S. Brinda, M. Singaravelu. Neonatal behavioral assessment among survivors of birth asphyxia using T.Berry Brazelton's NBAS. Int J Pediatr Res. 2018;5(5):258-262.doi:10.17511/ijpr.2018.i05.03. 